\title{
NATURAL HISTORY NOTE \\ Indian flying fox Pteropus giganteus is declining in lowland Nepal: Need of conservation actions
}

\author{
Hem Bahadur Katuwal ${ }^{1,2,3,}{ }^{,}$, Subash Kushwaha ${ }^{4}$, Rui-Chang Quan ${ }^{1}$
}

\begin{abstract}
${ }^{1}$ Southeast Asia Biodiversity Research Institute, Chinese Academy of Sciences, Yezin, Nay Pyi Taw, 05282, Myanmar, \& Center for Integrative Conservation, Xishuangbanna Tropical Botanical Garden, Chinese Academy of Sciences, Mengla, Yunnan, 666303, China

${ }^{2}$ University of Chinese Academy of Sciences, Beijing, 100049, China

${ }^{3}$ Small Mammals Conservation and Research Foundation, Kathmandu, Nepal

${ }^{4}$ Institute of Forestry, Tribhuvan University, Hetauda, Makwanpur, Nepal

* Corresponding author email: hembdrkatuwal@gmail.com

DOI: https://doi.org/10.14709/BarbJ.12.1.2019.08

Keywords: hunting, roosts, roost collapse, threats, tree felling

received: February, 11th 2019

accepted: August, 15th 2019
\end{abstract}

The Indian flying fox Pteropus giganteus (Brünnich, 1782) is the largest fruit bat in Nepal and forms large roosting colonies often close to human settlements in urban and rural areas (Acharya et al. 2010, Jnawali et al. 2011). Its diet consists of varieties of wild and cultivated fruits and flowers (Mahmood-ul-Hassan et al. 2010, Javid et al. 2017). It helps in seed dispersal and pollinates many flowering plants (Mahmood-ul-Hassan et al. 2010, Gulraiz et al. 2016). It is distributed across nine countries of South and South-East Asia, including India, Nepal, Pakistan, Bangladesh, Bhutan, Maldives, Sri Lanka, China and Myanmar (Molur et al. 2008). Although it is classified as Least Concern in the IUCN Red List of Threatened Species (https://www.iucnredlist.org/ species/18725/8511108), its population is declining both at global and national scale. This is predominately due to habitat loss and degradation, loss of large trees, reduction in food availability, introduction of power lines, hunting, etc. (Molur et al. 2008, Jnawali et al. 2011, Acharya 2015, Manandhar et al. 2017, Sharma et al. 2018).

In Nepal, the Indian flying fox was once abundant and a large population was previously distributed from Terai (lowland) to Mid-Hills (65-1500 m). However, due to multiple threats such as urbanization, hunting, habitat destruction, and lack of food (Acharya et al. 2010, Neupane et al. 2016), roosting colonies in several districts have shown dramatic population declines within the last decade. These include roosts from the Kathmandu valley, Kaski, Palpa, Sunsari, Morang, Jhapa, Saptari and Dang (Jnawali et al.
2011, Neupane et al. 2016). Known colonies of the Indian flying fox are not monitored and little is known about their current distribution within the country (Jnawali et al. 2011, Acharya 2015). Based on extensive fieldwork, we update the distribution status of the Indian flying fox in lowland Nepal and suggest conservation actions/measures aimed at reverting the on-going decline of the species.

We contacted key informants and local people to locate new roosting sites of the Indian flying fox across lowland districts of Nepal (elevation 60-125 m). We used binoculars to estimate the number of individuals and also informally interviewed local people/landowners $(n=50)$ to discover historic population trends for each roost and to identify existing threats impacting the colonies. During the survey, visiting once (August 2018-January 2019), we found 11 new colonies of the Indian flying fox across eight districts (Kapilvastu, Rupendehi, Parsa, Bara, Sarlahi, Dhanusa, Siraha and Sunsari) (Fig. 1, Table 1). Most of the interviewees reported tree felling and hunting as the causes for roost collapse in the six previously known localities: Taulihawa in Kapilvastu, Sekhauna and Dhangada in Sarlahi, Dhanusadham in Dhanusa, Itari in Siraha and Prakashpur in Sunsari (Fig. 1A). The estimated number of Indian flying foxes varied from 50-1800 individuals in the surveyed roosts (Fig. 1B-C, Table 1). Masala (Eucalyptus spp.), Sissoo (Dalbergia sissoo), Pipal (Ficus religiosa), Mango (Mangifera indica), and Simal (Bombax ceiba) were predominantly used roosting trees (Table 1), as reported in other studies (Acharya et al. 


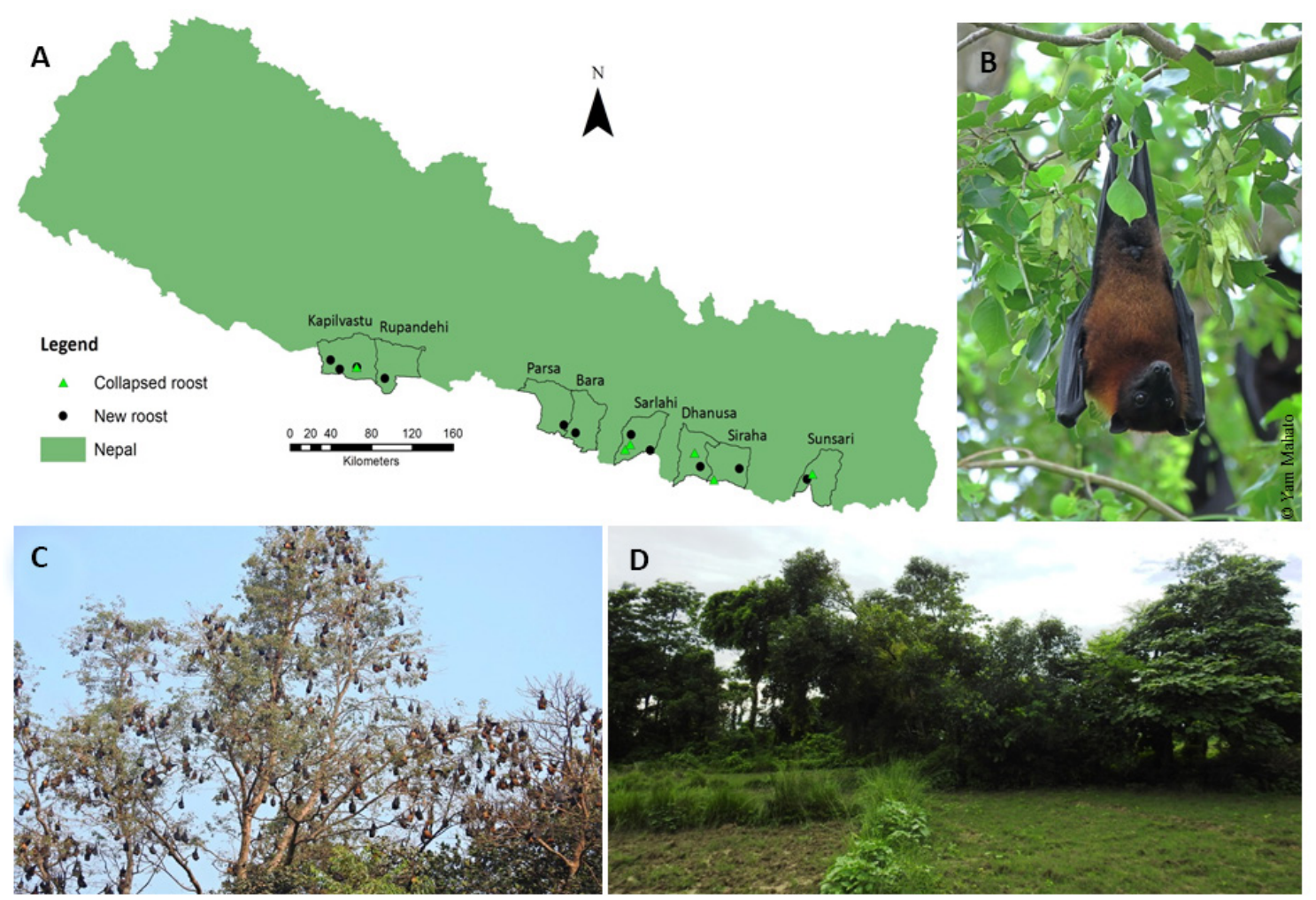

Fig. 1 - Roosting colonies of the Indian flying fox in lowland Nepal; A) map depicting the distribution of the colonies in different districts, B) adult Indian flying fox, C) colony of the Indian flying fox in Murtiya (Sarlahi) and D) roosting habitat in Dagdauwa (Kapilvastu).

2010, Jnawali et al. 2011, Neupane et al. 2016, Javid et al. 2017). Local names for the Indian flying fox included Baadur, Gaadur, Chamgudri and Banchat. Interviewees reported the destruction of the mango and other fruits by the Indian flying fox; however, they still demonstrated a positive attitude towards it. Locals reported the felling of roosting trees, and hunting by certain poor and marginalized people and seminomadic communities for example Nat/Karori, Chidimar, Satar, Kapadiya for bushmeats and that the belief of the Indian flying fox meat has medicinal properties, as the major cause for the declining populations (D.N. Mandal per.comm, D.R. Dahal per.comm., S. Khadka per.comm., S. Kushwaha per.comm., Table 1). Although bushmeat hunting for bats is currently uncommon in these areas, it is still known to occur in some places (Table 1). Fortunately, people in Narayanpur (Sarlahi) and Sahalesh Fulbari (Siraha) reported that religious beliefs safeguard colonies whose roosts are located within temple grounds and the sacred forest respectively.

Although most of the colonies of the Indian flying fox were recorded within locally-owned agricultural lands (Fig. 1D), close to settlements and roads, local people do not have knowledge on the ecological benefits and importance of the species. Locals continue to remove mature trees from their lands, largely because of their commercial value to furniture markets and construction works. These large trees are important roosting habitats for the Indian flying fox. As such tree felling is likely a main driver for the declining number of roosting bats observed in some colonies, reflecting reports made elsewhere in Nepal (Pokhara city; Sharma et al. 2018).

We have demonstrated that the Indian flying fox population is declining across the region (Table 1); supporting evidence of wider national population declines (Jnawali et al. 2011). Therefore, we strongly recommend the local governments and other relevant authorities to implement urgent conservation actions. Recommended conservation actions include: raising awareness among students and local people about the importance of the Indian flying fox in agro-ecosystems (e.g. erecting information boards to spread knowledge of the species), providing alternative livelihood options for low-income, marginalised and seminomadic communities to discourage hunting, establishing land-owner and fruit growers conservation incentives and appreciation, granting legal protection for potential roosting trees, enforcement of anti-hunting regulations, seasonal monitoring to capture temporal fluctuations in population size and distribution, and efforts to simultaneously reduce disturbance and habitat degradation in the wider landscape. These measures will help to ensure the coexistence of the Indian flying fox and people across the landscape. We also recommend a nationwide study of roosting colonies, in order to map vulnerable sites in need of priority conservation activities.

\section{ACKNOWLEDGMENTS}

This study was supported by CAS-SEABRI program (Y4ZK111B01). We would like to thank Yam Mahato, Jahirudin Musalman, Mannu Musalman, Samsulla Miya, Amir Khan, Sahajad Khan, Sabhir Hasan, Abbu Hasan, Ram Jiban Mahato, Shreeram Kushwaha, Rameshwor Thakur, Gangaram Sah, Zainodin Ansari, Jadoulal Kushwaha, Anish Timsina, Arjun Kurmi, Dev Narayan Mandal, Dibya Raj Dahal, Nitesh Das, Bharat Thakur, Laxman Chaudhary, Yogendra Yadav, Siyasaran Yadav, Saroj Khadka and all other local people for sharing crucial information on roosting colonies of the Indian flying fox. Similarly, we would like to thank Yam Bahadur Katuwal, Sanjan Thapa, Mingxia Zhang, Francis Commercon and three anonymous reviewers for their suggestions and comments on the manuscript. 


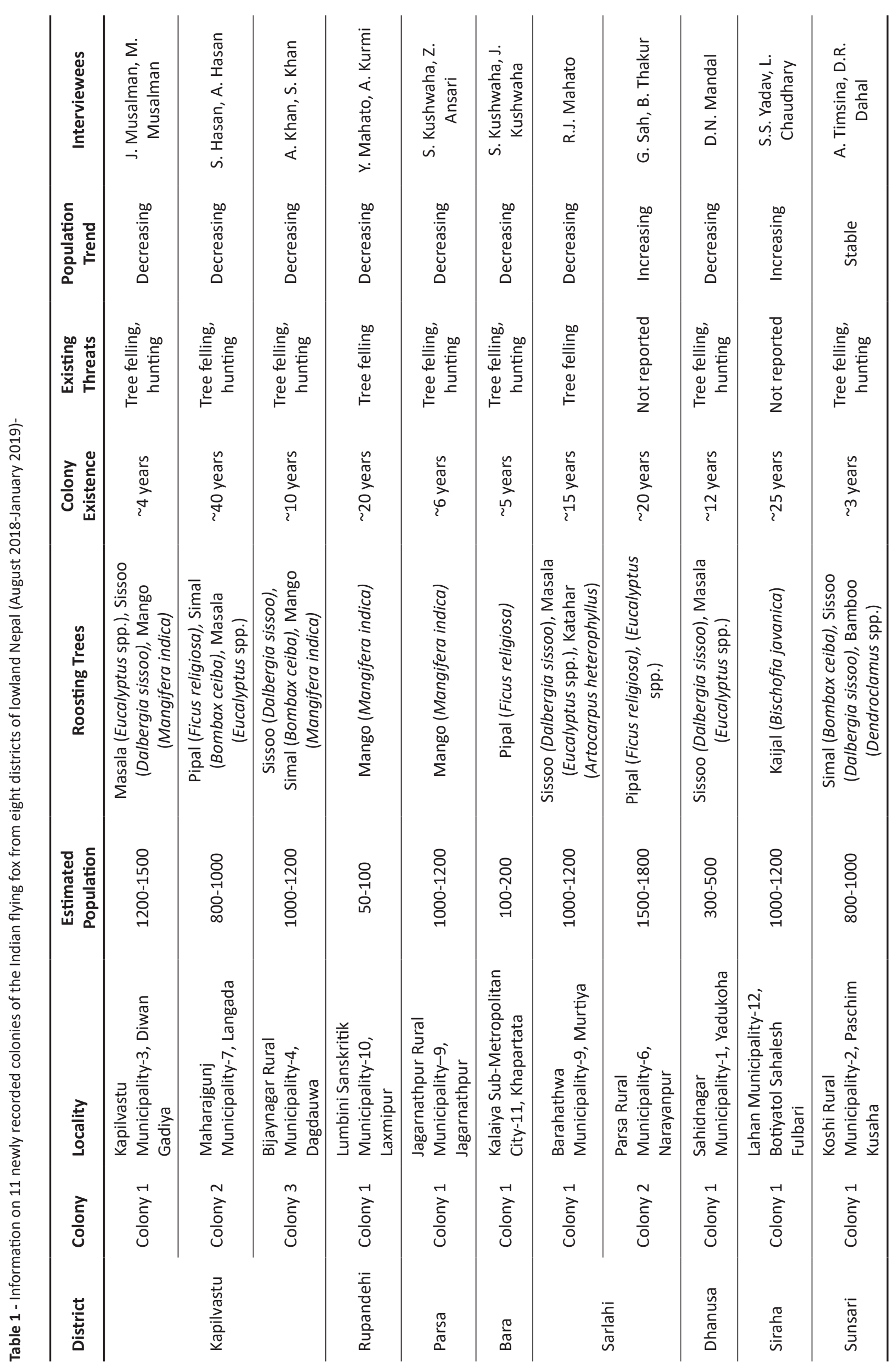




\section{REFERENCES}

ACHARYA, P.R. (2015). Conservation initiatives for fruit bats in Nepal. Project update report submitted to Rufford Foundation, United Kingdom.

ACHARYA, P.R., ADHIKARI, H., DAHAL, S., THAPA, A. \& THAPA, S. (2010). Bats of Nepal: a field guide. Small Mammals Conservation and Research Foundation (SMCRF), Kathmandu, Nepal, 114 pp.

GULRAIZ, T.L., JAVID, A., MAHMOOD-UL-HASSAN, M., HUSSAIN, S.M., AZMAT, H. \& DAUD, S. (2016). Role of Indian flying fox Pteropus giganteus Brünnich, 1782 (Chiroptera: Pteropodidae) as a seed disperser in urban areas of Lahore, Pakistan. Turkish Journal of Zoology, 40:417-422. http://doi.org/10.3906/zoo-1407-42

JAVID, A., GULRAIZ, T.L., ASHRAF, M., NADEEM, M., HUSSAIN, S.M., ALTAF, M. \& BABU, I. (2017). Proximate analysis of Indian flying fox's (Pteropus giganteus) natural food, with a note on its roost variations in urban areas of Lahore, Pakistan. Turkish Journal of Zoology, 41:714-721. https:// doi.org/10.3906/zoo-1512-24

JNAWALI, S.R., BARAL, H.S., LEE, S., ACHARYA, K.P., UPADHYAY, G.P., PANDEY, M., SHRESTHA, R., JOSHI, D., LAMICHHANE, B.R., GRIFFITHS, J., KHATIWADA, A. \& AMIN, R. (COMPILERS) (2011). The Status of Nepal Mammals: The National Red List Series. Department of National Parks and Wildlife Conservation, Kathmandu, Nepal, 206 pp.
MANANDHAR, S., THAPA, S., SHRESTHA, T.K., JYAKHWO, R., WRIGHT, W. \& ARYAL, A. (2017). Population status and diurnal behaviour of the Indian Flying Fox Pteropus giganteus (Brünnich, 1782) in Kathmandu Valley, Nepal. Proceeding of Zoological Society. http://doi.org/10.1007/ s12595-017-0219-x

MAHMOOD-UL-HASSAN, M., GULRAIZ, T.L., RANA, S.A. \& JAVID, A. (2010). The diet of Indian Flying-Foxes (Pteropus giganteus) in urban habitats of Pakistan. Acta Chiropterologica, 12(2):341-347. http://doi.org/ 10.3161/150811010X537927

MOLUR, S., SRINIVASULU, C., BATES, P. \& FRANCIS, C. (2008). Pteropus giganteus. The IUCN Red List of Threatened Species 2008: e.T18725A8511108.

NEUPANE, K. R., BASNET, K. \& KATUWAL, H.B. (2016). Plight of Indian Flying Fox (Pteropus giganteus) in lowlands of Eastern Nepal. World Journal of Zoology, 11 (2):81-85. http://doi.org/10.5829/idosi.wjz.2016.11.2.10355

SHARMA, B., SUBEDI, A., GYAWALI, K., GHIMIRE, P., BIST, B.S. \& BANIYA, S. (2018). Can Pteropus giganteus Brünnich, 1782 co-exist in a human dominated landscape? A case study in Pokhara valley, western Nepal. Journal of Bat Research and Conservation, 11(1). http://doi. org/10.14709/BarbJ.11.1.2018.06 